\title{
Beşinci Kola Karşı Halkla İlişkiler: Nadi ve Sertel'in Beşinci Kola Dair Kaleme Aldıkları Köşe Yazılarının Kamuoyunu Bilgilendirme Ekseninde Analizi
}

DOI: 10.26466/opus.959398

\author{
$*$ \\ Murat Basarır* \\ * Dr. Öğr. Üyesi, Erciyes Üniversitesi İletişim Fakültesi, Kayseri/Türkiye \\ E-Posta: muratbasarir@erciyes.edu.tr \\ ORCID: $\underline{0000-0003-2363-6370}$
}

\begin{abstract}
Öz
Bu çalışmanın amacı, İkinci Dünya Savaşı'nın başladığı ve Türkiye'ye sıçramasına yönelik endişelerin arttığ bir dönemde gündeme gelen beşinci kol faaliyetlerine dair kamuoyuna sunulan enformasyondaki çerçeveleri halkla ilişkiler açısından değerlendirmektir. Bu maksatla gerçekleştirilen doküman incelemesine bağh olarak 1940 yılında Cumhuriyet gazetesi yazarı Yunus Nadi ile Tan gazetesi yazarı M. Zekeriya Sertel'in beşinci kol faaliyetlerini konu alan köşe yazılarının varlığı tespit edilmiş ve bu yazllar amaçl örneklem olarak seçilmiştir. Seçilen köşe yazılarındaki enformasyon, nitel veri analiz programı Maxqda'da tematik kodlamaya tabi tutularak işlenmiş ve analizleri gerçekleştirilmiştir. Yapılan analizler neticesinde, ilgili yazarlarm 'beşinci kolu anlatma' ve 'beşinci kol faaliyetlerine karşı koyma' kategorileri içerisinde değerlendirilebilecek içerikleri kamuoyuna sundukları gözlenmiştir. Beşinci kolu açıklama kategorisinde referansların sunulduğu, betimlemelerin yapıldığı, örneklerin gösterildiğ i tespit edilmiş; karşı koyma kategorisinde ise milli birliği muhafaza ederek müteyakkız kalınması gerektiğinin vurgulandı ̆̆ı, kişilerden beşinci kola karşı tatbik etmeleri gereken tutum ve davranış kalıplarına yönelik örneklerin sunulduğu görülmüştür. Çalışma, beşinci kol faaliyetlerinin altın çağında, konunun Türk basınında eşik bekçilerince işlenişini ele almasıyla benzerlerinden ayrılmaktadır.
\end{abstract}

Anahtar Kelimeler: Halkla İlişkiler, beşinci kol, propaganda, kamuoyu, halkla ilişkiler tarihi. 


\title{
Public Relations against the Fifth Column: Analysis of Nadi and Sertel's Articles on the Fifth Column on the Axis of Informing the Public
}

\begin{abstract}
The aim of this study is to evaluate the frameworks of the information presented to the public about the fifth column activities, which came to the fore at a time when the Second World War started and the concerns about its spread to Turkey increased, in terms of public relations. Based on the document analysis carried out for this purpose, the existence of Cumhuriyet newspaper writer Yunus Nadi's and Tan newspaper writer M. Zekeriya Sertel's columns in 1940 on the fifth column activities have been determined and these articles have been selected as purposeful samples. The information of the selected columns has been processed and analyzed by thematic coding in the qualitative data analysis program Maxqda. As a result of the analyzes made, it has been observed that the relevant writers presented contents that can be evaluated in the categories of 'describing the fifth column' and 'opposing the fifth column activities', to the public. In the explanation category of the fifth column, it has been determined that references were presented, descriptions were made and examples were shown; in the category of resistance, it was seen that the necessity to be vigilant by preserving national unity was emphasized, examples of attitudes and behavior patterns that people should apply against the fifth column were presented. The study differs from its counterparts in dealing with the handling of the issue by the gatekeepers in the Turkish press in the golden age of fifth column activities.
\end{abstract}

Keywords: Public Relations, Fifth Column, Propaganda, Public Opinion, History of Public Relations. 


\section{Giriş}

1933-1945 yılları, Büyük Kriz ve İkinci Dünya Savaşı'ndan edinilen tecrübelere dayanarak halkla ilişkilerin geliştiği bir evre olarak ele alınmaktadır (Mardin, 1987, s.24). Savaş döneminde yaşanan askeri ve siyasi gelişmelere bağlı biçimde halkın tutum ve davranışlarında değişiklikler sergiletmek gayesiyle icra edilen iletişim uygulamaları, mezkûr dönemi halkla ilişkiler disiplini açısından değerli kılmaktadır. Nitekim İkinci Dünya Savaşı yılları halkla ilişkiler uygulamaları, kendine özgü taşıdığı karakterlere bağlı olarak ayrı bir kesit olarak sunulduğu gözlenmektedir (Broom and Sha, 2013, s.239). Bu dönemde bilgilendirme kampanyalarına dayanarak halkla ilişkiler yeniden bir propaganda aracı olarak görülmeye başlanmıştır (Akbulut, 2017, s.36). Halkla ilişkilerle propagandanın iç içe geçtiği uygulamalarla karşılaşılmaktadır. Özellikle ABD'de gazeteci Elver Davis tarafından kurulan ve programı yürütülen Savaş Bilgilendirme Ofisi'nin (Office of War Information- OWI) çalışmaları ile Almanya'da P. Joseph Goebbels' in Halkı Aydınlatma ve Propaganda Bakanlığı'nda yürüttüğü çalışmalar bu kapsamda ön plana çıkmaktadır (Başarır, 2020, s.965). Esasında karşıt bu iki yapılanmaya koşut diğer devletlerdeki benzer yapıların tümünün sunduğu çıktılar, savaşın devamında, yayılmasında, sonlanmasının ardından da kurulan yeni düzenin kabul edilmesinde roller üstlenmiştir. Zaten İkinci Dünya Savaşı sırasında propaganda her zaman ordulara eşlik eden hatta onlardan önce gelen bir olgu olarak görülmüştür (Domenach, 1995, s.16).

$\mathrm{Bu}$ açıdan savaş döneminin enformasyon üretim karakteri, etik kaygılar taşımayan bir iklim içerisinde yalana, hileye, bozgunculuğa dayalı manipülatif eğilimler barındıran bir tarzda ortaya çıkmıştır. Bu iletişim tarzı savaşın getirdiği yıkımla birlikte toplumların üzerinde bir korku, endişe ikliminin oluşmasına neden olmuştur.

İş bu eğilimlere bağlı oluşan iklim içerisinde, öne çıkan olgulardan birisi de ordulardan önce gelmesi gereken yere yerleşerek varlık gösteren beşinci kol faaliyetleridir. Beşinci kol, bir ülkede gizli olarak düşman için çalışan örgütü tanımlamaktadır (TDK, 2021a). İkinci Dünya Savaşı'nda beşinci kol, Müttefik ülkelerin iç cephelerinde yıkıcı çalışmalar yürüten Mihver ajanlarına verilen bir isimdi ve görevleri de sabotaj eylemlerine giriş- 
mek, korkuya, kafa karışıklığına sebebiyet vermek ve sonunda bir düşman istilasına yardım etmek olarak değerlendirilmekteydi (Loeffel, 2015, s.vii). Kavram, dönemin propaganda savaşlarında etkin kullanılması nedeniyle sıklıkla gündeme gelmiş, üzerinde tartışmalar yaşanmıştır. MacDonnell da $(1995$, s.9) bu durumdan hareketle kavramın altın çağının iki yıldan (1939-1940) hemen az sürdügüüü belirtmekte, ilaveten beşinci kola yönelik korkunun İkinci Dünya Savaşı ve sonrasındaki Soğuk Savaş döneminde de devam ettiğini vurgulamaktadır.

Bu arada kavramın İkinci Dünya Savaşı'nın başladığı ve Balkanlar'a yayılma endişelerinin arttığı bir evrede -MacDonnell'in tabiriyle kavramın altın çağında- Türk basınında da işlendiği gözlemlenmektedir. Beşinci kol çalışmalarına dair basında sunulan haberler, kaleme alınmış yazılar yer almaktadır. Bu çalışma da 1940 yılında Cumhuriyet gazetesi başyazarı Yunus Nadi ile Tan gazetesi başyazarı Zekeriya Sertel'in beşinci kol faaliyetlerine dair köşelerinde kaleme aldıkları yazıları, halkla ilişkiler bağlamında kamuoyuna sunulan içeriğin yapısal boyutu üzerinden konu edinmektedir.

Bu konumlandırmaya bağlı olarak çalışma, ilgili yazarların olguya dair gazetelerdeki köşe yazılarının kamuoyunu bilgilendirmede kullandıkları argümanlar, sundukları örnekler, yaptıkları izahatlar ve betimlemeler üzerinden analizlerinin yapılması üzerine inşa edilmektedir. Böylelikle olgunun halka/kamuoyuna nasıl bir çerçevede sunulduğu gösterilmek istenmektedir. İncelenen yazılarda olguya dair yapılan çerçevelemelerin halkla ilişkilerde kamuoyuna sunulan mesaj tasarımlarına yol gösterici olabileceğinden yola çıkılmaktadır. Diğer yandan olguya yönelik köşe yazılarında sunulan enformasyonun kamuoyunu bilgilendirme modeli bağlamında değerlendirilebilecek bir karakter barındırdığ 1 savıyla hareket edilerek Türkiye'deki halkla ilişkiler tarihi açısından mezkûr modele örnek olarak sunulabileceği düşünülmektedir.

Bundan dolayı çalışmada öncelikle propaganda, beşinci kol ve halkla ilişkiler ve kamuoyunu bilgilendirme modeli bağlamında kavramsal çerçeve sunulmuştur. Ardından araştırmanın metodolojisine dair bilgilere yer verilmiştir. Sonunda da bulgular üzerinden bahsedilen perspektife bağlı olarak analizler yapılmıştır. 


\section{Kavramsal Çerçeve}

İnsanların düşüncelerini, duygularını, inançlarını etkileyen ve yönlendiren farklı ve özel bir yöntem olarak görülen propaganda (Güllüoğlu, 2014, s.506), iktidarın kazanılması, kaybedilmesi ve sürdürülmesinde geçmişten günümüze kadar etkisi olan siyasi güç olarak kabul edilmektedir (Geçiklï, 1999, s.265). Bu kabul edişlere paralel olarak propaganda; "cebir ve tazyikten başka vasıtalarla, (başlıca semboller, vecizeler ve kıymetlerle) ihtilaflı meseleler karşısında muayyen bir kitlenin görüşünde ve gidişinde arzu edilen bir değişikliği yapmaya çalışmaktır" şeklinde tanımlanmaktadır (Berkes, 1942, s.6). Bu yönüyle propaganda, organize edilmiş ikna olarak değerlendirilir (Çetin, 2016, s.241). Tanımdan ve değerlendirmeden de anlaşılacağı gibi propaganda kitleye yönelik bir dil olarak söz ya da daha başka simgeler kullanarak kitlelerin tutumunu etkileme girişimidir. $\mathrm{Bu}$ girişimde propaganda bazıları iyi bilinmeyen çok karışık fizyolojik, ruhsal ve bilinç dışı mekanizmaları kullanarak bilim ve estetikten aldığ ilkelerle hareket eder (Domenach, 1995, s.18). Kişilerin fizyolojik, ruhsal ihtiyaçlarından hareketle onları eyleme yönlendirecek mesajlar tasarlar.

Mesajlar tasarlanırken olumsuz nitelemeler, parlak sözler, kesin olmayan ifadeler ve hileli referans kullanımına başvurulduğu gibi organik bağ (transfer) oluşturma, özdeşleşme sağlama, korku sunma, bir yönü ortaya koyma ve üslubu güzelleştirme gibi tekniklerden yararlanılabilir (Çïfï ve Yildirim, 2012, s.35-36). Bu tekniklerle sunulan mesajlar hem akılda kal1cılığı artırmakta hem de insanları davranışa da yönlendirebilmektedir.

Dolayısıyla amacı ve doğası gereğince sosyal kontrolün önemli bir vasitası olan propaganda, kitle psikolojisine hitap eden bir araç konumundadır (Çolak ve Aydar, 2020, s. 1047). Kişilerin dikkatlerini, onlara fark ettirmeyecek bir şekilde istenilen noktalara çekebilmektedir (Özer, 2019, s.16). Bu özellikleriyle esas gayesi muhatap kitleyi belirli bir düşünce yönünde ikna etme çabası olarak görülen propaganda kavramı ile 'yalan', 'aldatma' ve 'beyin yıkama' gibi kavramları iç içe geçebilmektedir (Çolak ve Aydar, 2020, s.1050). Propaganda eğilim belirleme ve zihin yapılandırma süreci olduğu gibi ortada olanın, bilinenin istenilenler kapsamında döndürülmesi, değiştirilmesi ve farklılaştırılmasını da kapsamakta ve aynı zamanda bunu ahlakilik ve dürüstlük barındırmadan her türlü taktiği, biçimi kullanarak yapabilmektedir (Çetin, 2016, s.241). 
Kullanılan taktik, yöntem ve amaçlara bağlı şekilde ortaya çıkan propaganda türlerinden birisi de beşinci koldur. Beşinci kol (fifthcolumn), gri propaganda içerisinde değerlendirilmekle birlikte sinsice etkileme, ahlaki yozlaştırmaya yönelik gizlice faaliyet gösteren kişilerin ileriki aşamada kara propaganda olarak etik dişı iş ve işlemlerini de kapsayabilmektedir (Özkan, 2018, s.84). Beşinci kol, ileride harp edilecek ülkeye tedricen girip yerleşen bir yapıyı anlatmaktadır (Şehïoğlu ve Doğanay, 2019, s.459).

Terimin yaratılması, milliyetçi bir lider ve General Franco'nun güvenilir teğmenlerinden biri olan General Emilio Mola'ya atfedilmektedir. Mola, Eylül 1936 da bir radyo yayında Madrid'e gidişleri sırasında şehre doğru ilerleyen dört ordu kuvvetinin yanı sıra, Madrid'in kendi içinde sabotaj ve benzeri eylemlerle saldırmaya hazır bir beşinci kola da sahip olduklarını öne sürdü (Loeffel, 2015, s.9). Bu öne sürüşle aslında Mola, beşinci kolun amacının ve çalışma tarzının da çerçevesi çizmekteydi. Madrid'in içerisinde kendilerine bağlı kişilerin varlığını iddia ediyor, onların kendi lehlerine hareket edeceğini haber vererek korku ve endişe tesis ediyordu. Tesis edilen korku ve endişeye bağlı olarak halkın tutum ve davranışları etkilenebiliyordu.

Beşinci kol faaliyetlerini yürütenler, düşman ülkeler adına faaliyet gösteren hedef ülkenin bizzat kendi vatandaşları arasından veya turist vb. gibi doğrudan dikkat çekmeyen kişiler arasından tercih edilerek belirlenmekte ve bunlar üzerinden propaganda faaliyetleri yürütülmektedir (Özkan, 2018, s.84). İlk etapta ilgili alanlarda kullanacağı elemanlar seçilerek barış zamanı uygun zemin hazırlamakta ve bu yapı gizli ordu haline girdiği ülkede savaş zamanı taarruza geçmektedir (Ertürk'ten aktaran: Şehïtoğlu ve Doğanay, 2019, s.459). Bu açıdan yabancı ajanlar, yerel işbirlikçiler ve aldatılmış düşmanlar beşinci kol gücünün belkemiğini oluşturmakta ve ev sahibi ülkeyi demoralize etmek, bölünmüş bir yapıya dönüştürmek ve askeri olarak savaşa hazırlıksız bırakmak için casusluk, sabotaj ve darbe girişimlerinde bulunabilmektedir (MacDonnell, 1995, s.3-4).

İş bu yönleriyle beşinci kol, Truva Atı hikâyesinin modern bir versiyonu olarak görülmektedir (Loeffel, 2015, s.vii). Dolayısıyla beşinci kol faaliyetlerinin adının geçtiği toplumda her an içerden darbe almaya, yıkılmaya yönelik bir endişe ortaya çıkmaktadır. Örneğin Almanya'nın Avrupa'da yıkıcı taktikleri görünüşte başarılı bir şekilde kullanmasının Amerika Birleşik Devletleri'nde güçlü bir etki yarattığı, Mart 1938 ile Temmuz 
1940 arasında meydana gelen olayların Amerika'da Beşinci Kol korkularını harekete geçirdiği ve rahatsız edici bir endişeyi ulusal bir histeriye dönüştürdüğü kaydedilmektedir (MacDonnell, 1995, s.109). Zaten beşinci kolun bütün derdi de sadece şuydu: 'bir korku' (Loeffel, 2015, s.2). Fark edileceği üzere beşinci kola dair üretilen söylemler, bir şeyin dedikodusunun yapılması, onun gerçekleşmesinden daha kötüdür anlamına gelen (TDK, 2021b) 'şüyuu vukuundan beter' deyişini doğrular niteliktedir.

Bu bağlamda beşinci kolun tesis etmeye uğraştığı endişe, korkuya karşı beşinci kol faaliyetinin icra edildiği yerdeki kamuoyunun bilgilendirilmesi ihtiyacı ortaya çıkabilmektedir. Halkla İlişkiler alanı da iş bu noktada vazife üstlenebilmektedir. Halkla İlişkiler anlayışı içerisinde karar alıcıların, kanaat önderlerinin beliren ihtiyaca bağlı olarak kamuları bilgilendirmeleri, olguya dair basın aracılığıyla çerçeveler sunmaları gerekebilir. Ne de olsa halkla ilişkiler, kimilerine göre enformasyonun yayılmasına, çatışmaların giderilmesine ya da karşılıklı anlayışın güçlenmesine hizmet etme durumundadır (Grunig, 2005, s.17). Bu açlardan beşinci kola dair kamularda üretilen söylemlere müdahale etmek istenebilecek ve bu müdahale kitle iletişim araçlarında eşik bekçileri ve kanaat önderleri gibi görev üstlenenler aracılığıyla yürütülebilecektir.

$\mathrm{Bu}$ istikamette basin üzerinden kamuoyunu bilgilendirmeye, etki tesis etmeye matuf içerikler halkla ilişkiler disiplininde bir değer taşıyacaktır. Nitekim halkla ilişkilerde kamusal enformasyon sununumu, kamuoyunu bilgilendirme, bir model olarak ele alınmaktadır. Ivy Lee'nin temsilcisi gösterildiği bu model, hedef kitlelere doğru ve gerçek bilgilerin verilmesini hedeflemektedir (Canöz ve Canöz, 2020, s.55). Ivy Lee, yüksek gücü olan bireylerin kamuyunu bilgilendirme sorumluluğu olduğu fikrini ortaya atarak modern halkla ilişkilerin kapılarını açmıştır (Seitel, 2016, s.33). 'Halkın aydınlatılmasını' temel alan bu yeni halkla ilişkiler anlayışının doğuşuna zemin hazırlayan olay basının olumsuzlukları ortaya çıkarmak için harcadığı çabaya bağlanmaktadır (Peltekoğlu, 2016, s.105). Basının olumsuzlukların nedeni, sonuçları, sorumluları üzerinden anlatılarına bağlı biçimde kurduğu baskının yansımasıyla doğru, net, hızlı bilgilendirilme isteği ortaya çıkmıştır.

Bu yüzden kamusal enformasyon modelinin karakteristik noktaları olguların, olayların, durumların açık, net bir biçimde kamulara anlatılma- 
sina dayanmaktadır. Tarhan da (2008, s.132), günümüzde kamuoyunu bilgilendirme modeli kamu yönetimlerinin halkla ilişkiler birimlerince hemen her zaman kullanıldığına dikkat çekmektedir. Kamu yönetimine bağlı teşkilatlanmalar ki hükümetlerde bunlar arasındadır ürettikleri içerikleri basınla geliştirdikleri ilişkiler vasıtasıyla kamulara aktarabilmektedir.

Kamu, belirli bir olay veya sorun etrafında belirli bir zamanda oluşan gruplar olarak bazen az katılımla bazen de toplumun genelini ilgilendiren konular etrafında geniş katılımla oluşmaktadır (Atabek, 2002, s.224). Kamuoyu ise bu kamularda yaşanan tartışmaların hacmine, yönüne, desteğine ve yansıtılmasına bağlı kalarak şekillenmektedir. Kapani'nin (1997, s.146) kamuoyuna dair "belirli bir zamanda, belirli bir tartışmalı sorun karşısında, bu sorunla ilgilenen kişiler grubuna veya gruplarına hâkim olan kanaat" tanımı da bu durumu doğrulamaktadır. Kamuoyu, bireysel görüşün grup görüşüne dönüştürülmesini içerir ve halkla ilişkiler çalışmalarının temelini oluşturan olgulardan biridir (Sezgin, 2007, s.179). Dolayısıyla çoğu halkla ilişkiler uygulaması söz konusu kanaatin geliştirilmesi için planlanır ve uygulanır. Sonuç olarak kamuoyu halkla ilişkilerde her daim desteği alınmaya çalışılan, lehe kanaat oluşturması istenen bir olgudur.

Beşinci kol gibi toplumun tamamını ilgilendiren, üstelik bir de savaş ortamında gündeme gelen bir olguya da hem kamuların hem de yönetimin duyarsız kalması beklenemez. Beşinci kol faaliyetlerine yönelik şayia halkın tutum ve davranışlarına yukarıda zikredildiği gibi bilhassa endişe ve korku temelli tesir edebilecektir. Bu nedenle halkın beşinci kola ilişkin bilgilendirilmesi gerekecek, kitle iletişim araçları da bu gerekliliğin giderilmesinde görev ifa edeceklerdir. Kitle iletişim araçlarında kamuya yayılan enformasyon bu tür durumlarda belirleyici olabilmektedir. Nitekim erken dönem kitle iletişim araştırmaları ekseriyetle tutum ve davranış özelliği üzerinde durmakta ve etkinin haberdar etme-farkındalık yaratma, bilgi edinme, tutum değişikliği ve davranış değişikliği şeklinde temelde dört aşamada gerçekleştiği ifade edilmektedir (Terkan, 2005, s.33). Anlaşılacağı üzere basın organlarında bir olguya dair sunulan bilgilerle, kamuların o olguya yönelik bilinç düzeyleri değiştirilebilmektedirler. Bu vesileyle basında kamuoyunda edişe ve korku tesis eden beşinci kol olgusuna dair yazılan yazılar, halkla ilişkiler açısından önemli materyaller olarak 
görülebilir ve bu materyallerde sunulan içeriğin yapısal boyutu halkla ilişkiler bağlamında değer taşımaktadır.

\section{Yöntem}

\section{Araştırmanın Amacı ve Kısıtlılı̆̆ı}

Çalışma, İkinci Dünya Savaşı yıllarında gündeme gelen beşinci kol mefhumunun muhtevasina dair kamuoyuna sunulan enformasyonu betimlemek ve halkla ilişkiler alanı üzerinden değerlendirmek için tasarlanmıştır. Bu nedenle uzun süren savaşın tüm dönemlerine değil de savaşın Balkanlara sıçramasına bağlı biçimde Türkiye' ye taşınmasının konuşulmaya başlandığı bir devirde gündeme gelen beşinci kol tartışmalarına odaklanmaktadir.

Bu odaklanmayla o yıllarda baskı sayısı yüksek olan gazetelerinden Tan ve Cumhuriyet üzerinde 1940 yılına dair yapılan doküman incelemesinde, dönemin önde gelen gazetecilerinden M. Zekeriya Sertel ve Yunus Nadi'nin beşinci kolu konu edinen köşe yazılarının varlığı tespit edilmiştir. Kitle iletişim araçlarında kendi köşeleri bulunan ve kamuoyunu bilgilendirme noktasında bir güce haiz mezkûr yazarların kamuya konuyu nasıl çerçeveleyip sundukları araştırılmak istenmiştir.

Tablo 1. Araştırmada İncelenen Belgelerin Künyesi

\begin{tabular}{|c|c|c|c|c|}
\hline Yazar & Makale Başlığı & Gazete & Tarih & Sayfalar \\
\hline $\begin{array}{l}\text { M. Zekeriya } \\
\text { Sertel }\end{array}$ & "Beşinci Kola Karşı Altıncı Kol" & Tan & 20.Ağu.40 & 1,2 \\
\hline $\begin{array}{l}\text { M. Zekeriya } \\
\text { Sertel }\end{array}$ & "Altıncı Kolun Vazifeleri" & Tan & 21.Ağu.40 & 1,2 \\
\hline $\begin{array}{l}\text { M. Zekeriya } \\
\text { Sertel }\end{array}$ & $\begin{array}{l}\text { "Altıncı Kol Uyanık ve Faaliyette- } \\
\text { dir" }\end{array}$ & Tan & 23.Ağu.40 & 1,2 \\
\hline Yunus Nadi & "Beşinci Kol, Hiyanet Kolu!..." & Cumhuriyet & 16.May.40 & 1,6 \\
\hline Yunus Nadi & "Her Memlekette Beşinci Kol" & Cumhuriyet & 30.May.40 & 1,6 \\
\hline Yunus Nadi & $\begin{array}{l}\text { "Bütün Milletçe Tutacağımı Tek } \\
\text { Yol Milli Birlik Yoludur" }\end{array}$ & Cumhuriyet & 5.Haz.40 & 1,6 \\
\hline
\end{tabular}

$\overline{\text { (Nadi, 1940a, s.1,6, 1940b, s.1,6, 1940c, s.1,6; Sertel, 1940a, s.1,2, 1940b, s.1,2, 1940c, s.1,2). }}$ 
Çalışma, beşinci kol faaliyetlerine bağlı yoğun endişelerin ve tartışmaların yaşandığı bir devirde, spesifik olarak bu konuyu işlemesi münasebetiyle, amaçlı olarak seçilen ve yukarıda tablo halinde künyesi sunulan belgelerdeki içerikler üzerine kurgulanmıştır. Bu bakımdan çalışmanın 1940 yılında Cumhuriyet ve Tan gazetelerinde mezkûr yazarların köşe yazıları bağlamında bir kısıtlılığı mevcuttur. Ayrıca konunun köşe yazıları d1şında gazetelerdeki diğer işleniş türleri -spotlar, haberler vb.- çalışmaya dâhil edilmemiştir.

\section{Araştırmanın Soruları}

Çalışma, yukarıda belirtilen kurgulanışa ve kısıtlılıklara bağlı olarak aşağıdaki araştırma soruları üzerine inşa edilmiştir;

1. Zekeriya Sertel ve Yunus Nadi, köşe yazılarında beşinci kolu nasıl kamuoyuna anlatmışlardır?

2. Zekeriya Sertel ve Yunus Nadi'nin konuyu kamuoyuna aktarırken ele aldıkları temalarda, kategorilerde farklılık mevcut mudur?

3. Beşinci kola dair yazılan bu yazılar dönemin basın ortamı ve halkla ilişkilerde kamuoyunu bilgilendirme modeli nazarından nasıl değerlendirilebilir?

\section{Araştırmanın Analiz Yöntemi}

İçerik, belirli etkilerin nedeni olması ve üretiminin önceki bağlamını, sürecini yansitması dolayısıyla incelenmektedir (Riffe vd., 2014, s.17). Bu nedenle bu çalışmada da araştırma sorularına bağlı olarak amaçlı örneklem olarak seçilen köşe yazılarındaki içerik Maxqda nitel veri analiz programı üzerinde içerik çözümlemesine tabi tutulmuştur. İçerik çözümlemesi, "kaydedilmiş enformasyonun içeriğini incelemek için geliştirilmiş sistematik herhangi bir yordam"dır ( Walizer ve Wiener'den akt. Atabek Şendur ve Atabek, 2007, s.20).

İçerik çözümlemesi, görsel/sözel ya da yazılı malzeme içeriğindeki eğilimleri belirlemek, haberlerin analizini yapmak, iletişim kaynakları arasında karşılaştırmada bulunmak, iletişim araç ve ortamlarının amaca uygunluğunu sunmak, iletilerde tema ve yan temaların belirlenmesinde kullanılmaktadır (Akdenizli, 2012, s.133). Bu çalışmada da beşinci kolu konu 
edinen yazılardaki temaları belirlemek, temalar kapsamında yazarlar arasındaki farkı bulmak, ele alınan konunun nasıl çerçevelendiğini tespit etmek için tercih edilmiştir. İçerik çözümlemesi yapılırken incelemeye tabi tutulan köşe yazıları üzerinde çoklu okuma gerçekleştirilmiş ve okumalar esnasında yazılanlar üzerine notlar alınarak kodlamalar yapılmıştır. Kodlanan yerler daha sonra Maxqda programının sunduğu yaratıcı kodlama imkânı ile tümevarımcı yaklaşımla temalara daha sonrasında da kategorilere dönüştürülerek sistematik bir yapıya kavuşturulmuştur. Böylelikle köşe yazılarının içeriği ortaya çıkartılan kodlar temalara, temalar kategorilere ayrılmış ve muhteva analiz yapılacak tarzda sayısal verilere dönüştürülmüştür. Bu sayede belgeler ve kodlara bağlı olacak şekilde yazılara dair vaka analizleri, kod matris taramaları, hiyerarşik kod-alt kod modelleri çıkartılabilmiştir.

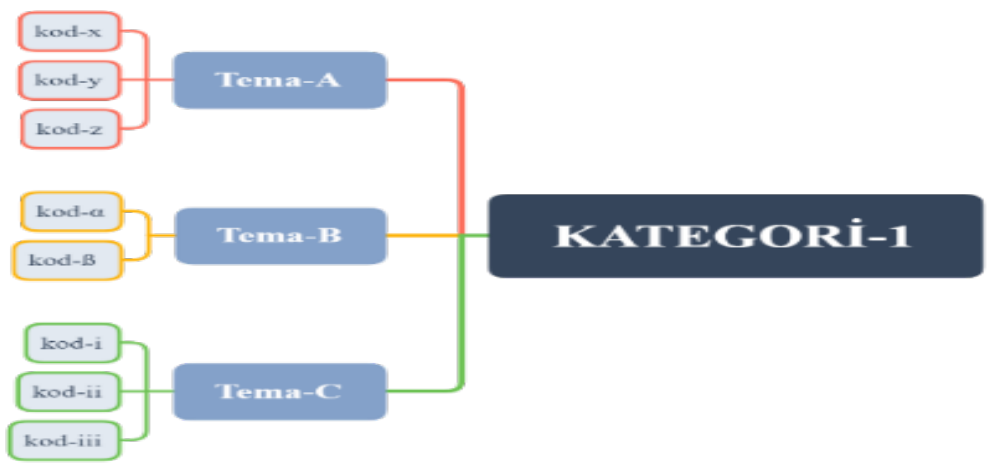

Şekil 1. Kategori Oluşturma Süreci

\section{Bulgular}

\begin{tabular}{|l|c|c|c|}
\hline Kod Sistemi & Yazar=Sertel & Yazar=Nadi & TOPLAM \\
\hline$>$ @BEŞİNCI KOLU AÇIKLAMA & 25 & 44 & 69 \\
$>$ @BEŞİNCI KOLA KARŞI KOYMA & 17 & 22 & 39 \\
$\sum$ TOPLAM & 42 & 66 & 108 \\
\hline
\end{tabular}

Şekil 2. İncelenen Belgelerdeki Ana Kategorilerinin Kod Matris Taramast 
Şekil 2'de beşinci kola dair incelenen belgelerde toplam 108 kodlama yapıldığı görülmektedir. Bunlar üzerinde gerçekleştirilen yaratıcı kodlama faaliyeti sonucunda 'Beşinci Kolu Açıklama' ve 'Beşinci Kola Karşı Koyma' başlıklarında iki (2) ana kategorinin ortaya çıktığı anlaşılmaktadir.

Belgeler üzerinde üretilen yüz sekiz (108) kodun altmış dokuz (69) âdeti Beşinci Kolu Açıklamaya yönelik iken otuz dokuz (39) âdeti Beşinci Kola Karşı Koymaya dairdir. Nadi'nin yazıları üzerinde altmış altı (66), Sertel'in yazıları üzerinde ise kırk iki (42) kodlama yapılmıştır. Beşinci Kolu Açıklama kategorisi içerisinde Sertel' in yazılarında yirmi beş (25), Nadi'nin yazılarında kırk dört (44); Beşinci Kola Karşı Koyma Kategorisinde ise Sertel'in yazılarında on yedi (17), Nadi'nin yazılarında yirmi iki (22) kod üretiminin gerçekleştirildiği görülmektedir.

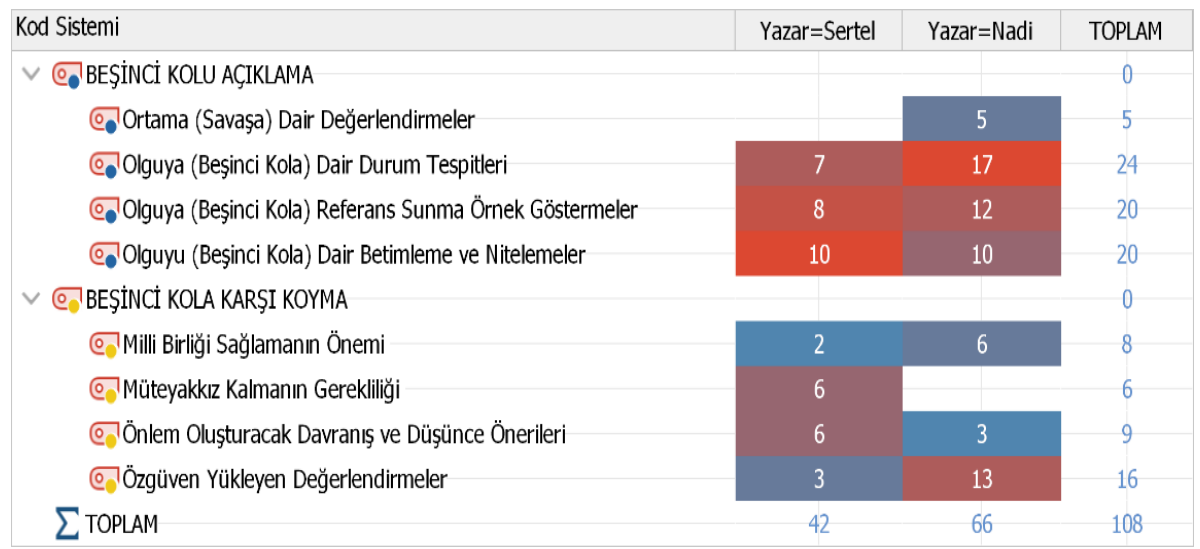

Şekil 3. Kategoriler Içerisindeki Temaların Kod Matris Taraması

Şekil 3'de Beşinci Kolu Açıklama ve Beşinci Kola Karşı Koyma kategorileri içerisinde yer alan temaların frekansını göstermektedir. Her iki kategoride de dört adet temanın belirdiği görülmekte ve Nadi ile Sertel'in yazılarında ilgili temalara dair üretilen kodların frekansı sunulmaktadır. Beşinci Kola Dair Betimleme ve Niteleme temasının dışındaki diğer temalarda yazarların yazılarından üretilen kod frekanslarının farklı olduğu tespit edilmektedir. 


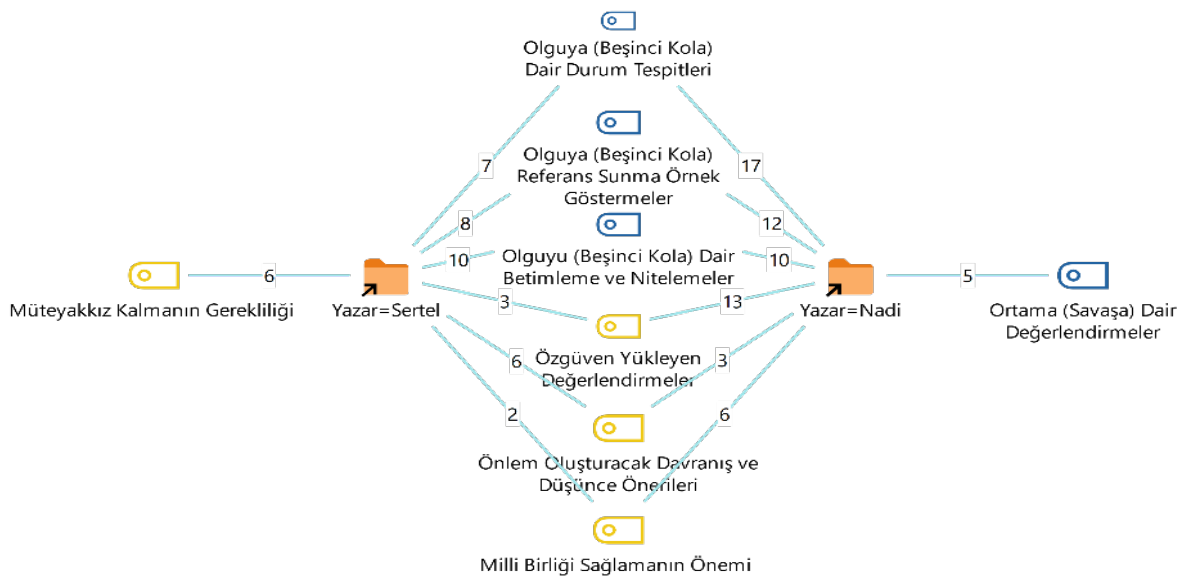

Şekil 4. Kümelendirilmiş Belgeler Üzerinden Üretilmiş Temalara Bağlı Biçimde M. Zekeriya Sertel-Yunus Nadi İki Vaka Modeli

Şekil 4'de Nadi ve Sertel'in yazılarındaki kodlar İki Vaka Modeli üzerinden analiz edildiğinde, yazarların ortak altı (6) temalarının mevcut olduğu iki (2) temada (Müteyakkız Kalmanın Gerekliliği ve Savaşa Dair Değerlendirmeler) ise bağımsız kaldıkları görülmektedir.

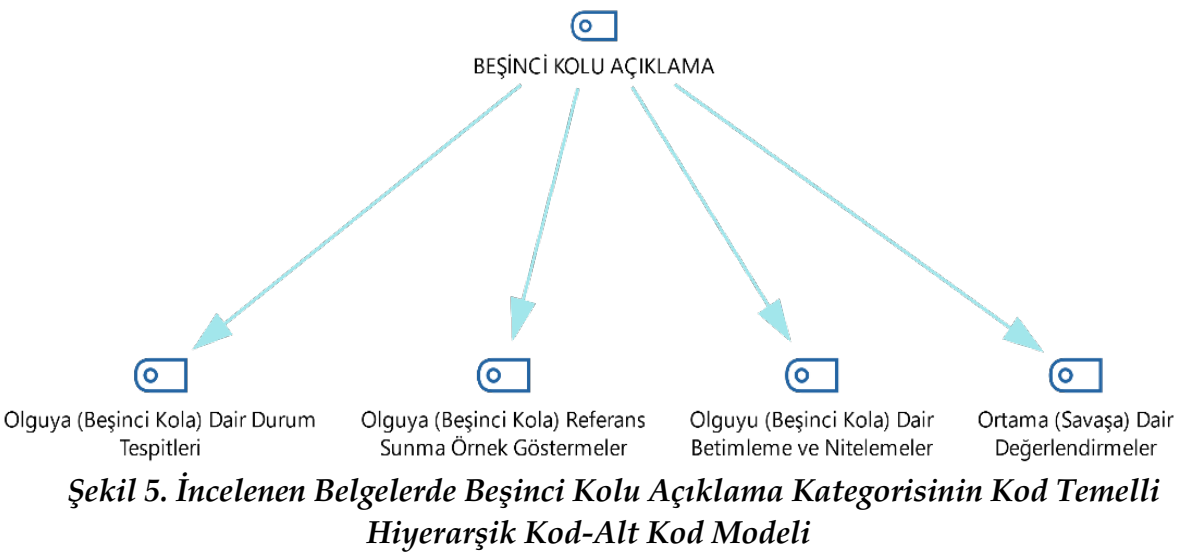

Şekil 5'den anlaşılacağ üzere incelenen belgelerde gerçekleştirilen yaratıcı kodlama sonucunda Beşinci Kolu Açıklama kategorisi içerisinde dört tema ortaya çıkmıştır. 
Beşinci Kola Dair Durum Tespiti temasındaki kodlu bölümlerde özetle bu savaşın icatlarından olan beşinci kolun propagandanın bir simgesi olduğu belirtilmekte, bu faaliyete cevap vermenin doğallığından bahsedilmekte, her ülkede görüldügünden bahisle ibret alınacak fevkaladelikler barındırdığı vurgulanmaktadır. Olguya Referans Sunma Örnek Gösterme temasındaki kodlanmış bölümlerde ise özetle Polonya, Norveç, Fransa, Hollanda, Belçika, Çekoslovakya işgalleri, bu işgallerde kendi memleketleri aleyhine faaliyet yürütenler, bu memleketlerin korkaklıkları örnek mahiyetinde sunulmaktadır. Hollanda ve Belçika'da rahip kıyafeti, milli asker kıyafeti giyen paraşütţülerden bahsedilmektedir. Rauşnig'in Hitler bana dedi ki adlı kitabında yazılanlara, Hitlerin sözlerine referanslar yapıldığı görülmektedir. Olguya Dair Betimleme ve Nitelemeler temasındaki kodlarda ise özetle olgunun casusluk şebekesi, hıyanet şebekesi, zehir saçan mikroplar, haysiyet bakımından düşüklük gibi betimlemelerle anlatıldığı dikkat çekmektedir. Bozguncu fikirler yaydığı, yeni bir garibe olarak milli ve mahalli nazileler yarattığı, münevver ve yarı münevverlerde görüldüğü gibi nitelemelerle karşılaşılmaktadır. Ayrıca beşinci kol sözünün herhangi bir memlekete taarruzdan evvel o memleket dâhilinde kurulup yürütülen casusluk teşkilatına, bu teşkilatta memleket halkından elde edilmiş insanlara ve nihayet sırası gelince bunlardan istifade için yapılan hareketlere tahsis edilmiş bir tabir olduğu belirtilmektedir. Savaşa Dair Değerlendirmeler temasında da özetle çok çetin geçen bu savaşın medeniyetin mağlubiyeti ile sonuçlanmayacağı, Türkiye'nin aldığı tedbirlerle Balkanlar'da ve Akdeniz'de istikrar sağladığı, halkın Yugoslavya'yı kuşatan tehlikelerden ve buna dair alınan tedbirlerden haberinin olmad1ğına dair bilgiler yer almaktadır.

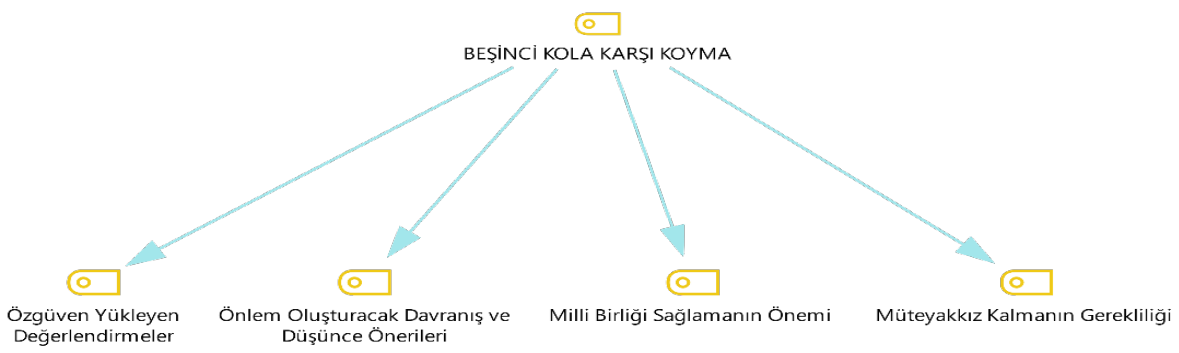

Şekil 6. İncelenen Belgelerde Beşinci Kola Karşı Koyma Kategorisinin Kod Temelli Hiyerarşik Kod-Alt Kod Modeli 
Şekil 6'dan anlaşılacağı üzere incelenen belgelerde gerçekleştirilen yaratıcı kodlama sonucunda Beşinci Kola Karşı Koyma kategorisi içerisinde dört tema ortaya çıkmıştır.

Özgüven Yükleyen Değerlendirmeler temasında özetle beşinci kol gelsin de bizim çelik sinirlerimizi bozsun, biz paçalarını salıverecek insanlar değiliz, biz boyunlarını bıçağa uzatan koyunlar değiliz gibi ifadelere yer almaktadır. Ayrıca altıncı kol vazifelerini bilir ve tatbik ederse, beşinci kolun faaliyet sahası bulamayacağı, hükümetin aldığı tedbirleri memnuniyetle karşılamamanın mümkün olmadığı, Türklerin hürriyet ve istikbalini hiç bir keyfe ve hiç bir kuvvete kurban edecek insanlar olmadıkları gibi söylemler bulunmaktadır. Önlem Oluşturacak Davranış ve Öneriler temasında ise susmasını bil, yerin kulağı vardır unutma, sır verme, bozgunculara maskelerini düşür, hilelerini çıkart, zehirlerini yaymaya mani ol, yabancı radyoları dinleme, propaganda neşriyatına kulakları kapa, yabancı gazete ve mecmuaları eve sokma, yabancilarla teması kes, temasa mecbur olduğunda memleket işlerinden bahsetme denilmektedir. İlaveten Fransa ve İngiltere ile yapılan anlaşmalara yönelik cihanı yakmaya hazırlanan ateş karşısında en makul ve en zaruri tedbir biçiminde cevap verilmesi salık verilmektedir. Milli Birliği Sağlamanın Önemi temasında da her vatandaşın beşinci kola karşı mücadelede muvazzaf olduğu, bütün Türk vatandaşlarının hükümetle hemehank olarak çalışmaya mecbur bulunduğu, memleketin en mühim müdafaasını teşkil eden ilk silahımızın milli birlik olduğu aktarılmaktadır. Ayrıca Türkiye'nin harici emniyetinde evvela kendi milli birlik ve kuvvetine dayandığı, vatanın emniyet ve selameti bahis mevzuu olduğu zaman bütün vatandaşların yekpare bir kaya ve aşılmaz bir kale halinde birleşmeleri zarureti ile bütün memleketin TBMM ile İnönü'nün ve hükümetin etrafında sımsıkı toplanmış ve birleşmiş halde bulunduğu vurgulanmaktadır. Müteyakkız Kalmanın Gerekliliği temasinda ise bozguncu propaganda yapmak isteyenlere karşı her Türk vatandaşı uyanık olmaya çağrıldığı, bilhassa gençlerin propaganda neşriyatına karşı altıncı kolun lideri olacak surette hazırlıklı ve uyanık bulunmaları gerektiği dile getirilmektedir. Ayrıca beşinci kolu bozguna uğratacak kuvvet hükümetin kanuni ve idari tedbirleri kadar belki ondan ziyade vatan- 
daşların uyanıklığında görülmekte, beşinci kola karşı uyanık ve faal olması lazım gelen zümrenin münevver ve yarım münevverler olduğu kaydedilmektedir.

\section{Tartışma ve Sonuç}

Tetkik eserlerde konuyla ilgili yazılanlar ile içerik analizine tabi tutulan köşe yazılarından elde edilen bulgular ilk araştırma sorusu kapsamında değerlendirmeye tabi tutulduğunda, hem Sertel'in hem de Nadi'nin beşinci kol mefhumunu, kamuoyuna hem açılamak hem de beşinci kol faaliyetlerine karşı önlem almak açısından iki boyuttan ele alarak işledikleri görülmektedir. Beşinci kola dair tanımlamalar yaptıkları ve doğurduğu sonuçlar üzerinde değerlendirmelerde bulundukları anlaşılmaktadır. Kamuoyunun beşinci kol faaliyetlerinin fenalığını anlaması için kavram üzerinde betimlemeler yapıldı̆̆ı dikkat çekmektedir. Bütün dünyayı saran bir fenalık olarak görülen faaliyetler demokrasilerde ancak vatana hiyanetle tasvir edilebileceği vurgulanmaktadır. Bozgunculukla eş tutulan beşinci kol faaliyetlerine katılım gaflet, düşüklük ve safdillikle açıklanmaktadır. Hatta Nadi kavrama efradını cami ağyarını mani bir tanım getirerek "beşinci kol sözü herhangi bir memlekete taarruzdan evvel o memleket dâhilinde kurulup yürütülen casusluk teşkilatına ve orada memleket halkından elde edilmiş insanlara ve nihayet sırası gelince bunlardan istifade için yapılan hareketlere tahsis edilmiş bir tabir" biçiminde sunmaktadır (Nadi, 1940a, s.1). Açıklama kategorisinde iş bu tanımlamaların dışında beşinci kolun daha akılda kalıcı olmasını sağlamak için bir de örnekler verildiği gözlenmektedir. Verilen örneklerle beşinci kolun yürütülüşs şekillerine, bunu yapanların beslendikleri kaynaklara ve doğurduğu sonuçlara dair kamuoyuna çerçeveler sunmaktadır. Sunulan çerçevelerde Polonya, Fransa, Hollanda, Belçika, Çekoslovakya işgalleri beşinci kol faaliyetlerinin sonuçları olarak örnek gösterilmektedir. Bununla birlikte kıyafet değiştirerek -kadın ve rahip kıyafeti- inen paraşütçülerden bahsedilmektedir ki bu örnekler kamuoyunda olguya dair dikkat çekme, konuya ilgi uyandırma nazarından halkla ilişkiler kapsmında değer taşımaktadır. Diğer yandan Rauşning'in 'Hitler bana dedi kitabından alıntılar yapılarak Hitler'in penceresinden beşinci kol çalışmalarında nüfuzlu kişilerin satın 
alınması, hırs, parti düşmanlığı ve başa geçme hülyası gibi saiklerle kendiliğinden beşinci kola dâhil olanlarla askeri güç kullanmadan daha ucuza düşmanı mağlup etmenin gerçekleştirilebileceği aktarılmaktadır. Bu referans gösterme okuyuculara beşinci kol faaliyetlerinin maksadını planlayıcılarının dilinden aksettirmesi bakımından halkla ilişkiler açısından değerlidir. Açıklama kategorisine beşinci kola dair durum tespitleri ve değerlendirme açısından bakıldığında ise bu savaşta beşinci kolun icat edildiği, yaygın şekilde kullanıldığı, bu stratejiye izin verecek demokrasinin olamayacağı, tepki göstermenin doğal karşılanması gerektiği aksettirilmektedir. Kisaca açıklama kategorisindeki kodlar göstermektedir ki yazarlar, halka/kamuoyuna beşinci kol çabalarının iç bağlantılarla sağland1ğını, bu savaşta yaygın kullanıldığını, uygulayıcıları açısından yürütüldüğü yerde taraftar temin ederek mağlup olmaya zemin oluşturduğu yönünde bir kavrayış kazandırma gayreti içerisindedirler.

Analize bağlı anlaşılmaktadır ki yazarlar beşinci kolun kavranmasına müteakip ona karşı koymada esas alınacak yaklaşım tarzlarını da gündeme taşımakta ve kamuoyuna çerçeveleyip sunmaktadırlar. Bu kategoride sundukları çerçeveler beşinci kola karşı uyanık kalma, milli birliği tesis etme, karşı koymayı kolaylaştıracak davranış kalıpları kazanma ve toplumsal moralleri yüksek tutmaya yarayan telkinlerden oluşmaktadır. Beşinci kolla mücadele bir vazife telakki edilmekte, ona karşı gelmede milli birliğin bir silah metaforuna dönüştürüldüğü fark edilmektedir. Aynı zamanda vatanın emniyeti söz konusu olduğunda beraber hareket etmek gerektiğinin altı çizilerek hükümet etrafında sıkı tutunmak gerektiği okuyuculara sunulmaktadır. Beşinci kola dair güven aşılayan çerçevelere baktığımızda ise azim ve kararlılıktan, başka milletlere benzememekten, çelik sinirlere sahip olmaktan ve dostluklara mertlikle sahip çıkmaktan bahsedildiği belirmektedir. Bu açıdan kamuoyuna öz güven aşılanırken hamasi bir tarzın benimsendiğinden bahsedilebilir. Bu kategoride son olarak beşinci kola karşı koymak noktasında takip edilecek davranışlarda ise spesifik önerilerin getirildiği görülmektedir. Okuyuculara sir vermeme, yabancılarla konuşmama, onların yayınlarına kulak tıkama gibi sergileyecekleri tutum ve davranışa dair telkinde bulunulmaktadır. Burada dikkat çeken bir tutum beklentisi Nadi'den gelmektedir. Nadi, İngiltere ve Fransa ile yapılan anlaşmalara bağlı olarak gelecek serzenişlere 
karşı 'cihanı yakmaya hazırlanan ateş karşısında en makul ve zaruri tedbir' biçiminde cevap verilmesi gerektiğini okuyucuya aktarmaktadır. Beşinci kola karşı önlem alma kategorisinde halka/kamuya kısaca, uyanık bir halde, milli birliğe dayanarak, yabancı telkinlerden uzak kalarak, kendine güvenmekle sağlanabileceğine dair çerçeve çizilmektedir.

İkinci araştırma sorusuna bağlı değerlendirme yapıldığında, Sertel ve Nadi'nin beşinci kolu açıkla/örnek ver/davranış kalıbı öner şeklinde formülize edilecek tarzda sundukları anlaşılmaktadır. Bununla birlikte üsluplarının ve ele alınan temaların yoğunluklarının değiştiği göze çarpmaktadır. Sertel, müteyakkız kalma; Nadi ise savaşa dair değerlendirmeler temalarına sahiplik açısından birbirlerinden ayrılmaktadır. Sertel, beşinci kola dair uyarılarında milletin tamamı hedef almaktadır. İş bu hedef alış kendini uyarılardaki 'her Türk', 'tüm vatandaşlar' ifadeleri üzerinden açığa çıkarmaktadır. 'Sıradan' vatandaşa güvenmekle birlikte beşinci kola teşne zümre olarak aydın ve yarı aydın zümresini görmekte ve dahi onlara dair çekinceler ortay koymaktadır. Nadi ise savaşa dair değerlendirmelerinde savaşın çetin geçeceğini, medeniyetin mağlubiyetiyle sonlanmayacağını, Türkiye'nin aldığı tedbirlerle şu ana kadar Balkanlar'da ve Akdeniz'de istikrara şahitlik ettiğini iddia etmektedir.

Üçüncü araştırma sorusu kapsamında değerlendirme yapıldığında ise öncelikle en açık şekilde beliren durum, savaşın Balkanlara sıçramasıyla coğrafi açıdan Türkiye'ye yaklaşması hadisesidir. Bu yaklaşma, beşinci kol faaliyetlerinin gündeme gelmesini tetikleyen bir durum olarak değerlendirilebilir. Savaşın yaklaşmasıyla beraber beşinci kol çalışmalarının ivme kazanacağı düşünülerek halkın bu konuda bilgilendirilmesi ihtiyacı hâsıl olmuştur. Bulundukları konuma bağlı sahip oldukları köşe aracıl1ğıyla Nadi ve Sertel'in sundukları bilgi sübvansiyonları aracılığılyla kamuoyunun beşinci kola yönelik duyarlılıklarını artırma, izleyecekleri davranış kalıpları aktarma ve dayanışma sağlama fonksiyonlarını yerine getirdikleri söylenebilir. Bu açıdan bu yazılar birer halkla ilişkiler örneği olarak görülebilir. İnsanlarda korku ve endişe uyandıran bir olguya ilişkin halkın aydınlatılması, iş bu aydınlatma eyleminde tasarlanan ve sunulan içeriğin yapısı, halkla ilişkiler disiplini açısından önemlidir. Özellikle endişe, korku uyandıran bir duruma ilişkin yapılan nitelemelerle ondan kurtulmak için verilen öğütler, mesajların ilgi uyandırma ve eyleme yönlendirme özelliklerini temsil eder niteliktedir. 
Bununla birlikte Nadi ve Sertel'in beşinci kola dair kamuoyuna sundukları bu çerçevelemeler, halkla ilişkiler tarihi açısından da değer barındırmaktadır. Bilhassa alan yazında halkla ilişkiler tarihi anlatılırken Ivy Lee' nin çalışmaları kamuoyunu bilgilendirme modelini açıklanırken örnek olarak sunulmakta Türkiye'deki uygulama örneklerine ise çoğunlukla yer verilmemektedir. Bu çalışma, kamuoyunu bilgilendirme modeline yine modelin çıtığı dönemin hemen sonrasında Türkiye üzerinde örnek olarak sunulabilecek bir yapı arz etmektedir. Son olarak çalışmada halka kanaat önderlerince sunulan çerçevelerin benzerlerinin daha sonraki yıllarda, ne tür durumlarda, hangi aktörlerce kullanıldığı üzerine çalışmalar yapılabilir. 
EXTENDED ABSTRACT

\title{
Public Relations against the Fifth Column: Analysis of Nadi and Sertel's Articles on the Fifth Column on the Axis of Informing the Public
}

\author{
Murat Başarır \\ Erciyes University
}

During the Second World War, communication practices carried out to make changes in the attitudes and behaviors of the people makes the mentioned period valuable in terms of public relations discipline. The "information production character" of the war period exhibits manipulative tendencies based on lie, deception and defeatism in a climate that does not have ethical concerns. Among these trends, one of the prominent phenomena in the said period is the activities of the fifth column, which settled in important places before the armies.

The fifth column defines the organization which also aims to establish anxiety and fear in a country that works secretly for the enemy. This concept has come to the fore frequently due to the effective use of the period in propaganda wars, and even the years 1939-1940 were described as the golden age of the fifth column. It has been observed that the concept was also covered in the Turkish Press at a time when the Second World War started and the concerns about its spread to Turkey increased. This study deals with the articles written in 1940 by Cumhuriyet newspaper editorin-chief Yunus Nadi and Tan newspaper editorial writer Zekeriya Sertel in their columns on fifth column activities.

The study aims to evaluate the frameworks in the information presented to the public regarding the fifth column activities in terms of public relations. For this purpose, the study was designed to analyze the articles written by the related authors in the newspapers about the phenomenon, based on the arguments they used, the examples they presented, the explanations and descriptions they made. On the other hand, it is thought that the information presented in the column articles about the phenomenon can be presented as an example of the aforementioned model in terms of the history of public relations in Turkey, with the argument that it has 
a character that can be evaluated in the context of the public information model. Based on these purpose, design and thoughts, the study is built on the following research questions;

1. How did Zekeriya Sertel and Yunus Nadi explain the fifth column to the public in their columns?

2. Are there any differences in the themes and categories that Zekeriya Sertel and Yunus Nadi discuss while conveying the issue to the public?

3. How can these articles about the fifth column be evaluated in terms of the press environment of the period and the public information model in public relations?

In this study, the content of the columns selected as purposive sampling depending on the research questions was coded in the Maxqda qualitative data analysis program and subjected to content analysis. First of all, multiple reading was carried out on the columns that were examined during the content analysis. Coding was done by taking notes on what was written during each reading. The coded places were then divided into themes with an inductive approach with the creative coding opportunity offered by the Maxqda program, and then transformed into categories and brought into a systematic structure. In this way, case analyzes, code matrix scans, hierarchical code-subcode models of the articles were extracted depending on documents and codes and analyzes were carried out with the findings.

In this context, when the findings were interpreted within the scope of the first research question, it was observed that the relevant authors presented the contents that could be evaluated in the categories of 'explaining the fifth column' and 'opposing fifth column activities'. In the explanation category of the fifth column, it was determined that references were presented, descriptions were made, examples were shown. In this category, the fifth column is considered as an evil that surrounds the world and is equated with defeatism. Participation in the activities of the fifth column is explained through heedlessness, inferiority and naivety. The occupations of Poland, France, the Netherlands, Belgium and Czechoslovakia are presented to the readers as a product of the activities of the fifth column.

In the category of resistance, it was seen that it was emphasized that it was necessary to stay vigilant by preserving national unity, and examples 
were presented about the attitude and behavior patterns that they should apply against the fifth column. Suggestions regarding the attitude and behavior to be exhibited such as keeping secrets, not talking to strangers, not listening to their broadcasts draw attention.

When evaluation based on the second research question is made, it is noticed that Sertel and Nadi presented the fifth column in a way that would be formulated as explain/give an example/suggest a behavior pattern. However, it is striking that their styles and the intensities of the themes discussed have changed. Sertel differs from each other in terms of having the themes of keep vigilance and Nadi evaluations about the war. Sertel targets the entire nation in its warnings about the fifth column. This targeting reveals itself through the expressions 'every Turk' and 'all citizens' in the warnings. Although he trusts the 'ordinary' citizen, he sees the intellectual and semi-intellectual groups as the target group in the fifth column and reveals his concerns about them. Nadi, on the other hand, claims that the war will be tough, that it will not end with the defeat of civilization, and that Turkey has witnessed stability in the Balkans and the Mediterranean with the measures taken so far.

When the evaluation is made within the scope of the third research question, the most obvious situation firstly is the fact that the war is getting closer to Turkey geographically, with the spread of the war to the Balkans. This approach can be considered as a situation that triggers the fifth column activities to come to the fore. Considering that the work of the fifth column would gain momentum with the approach of the war, the need to inform the public on this issue arose. It can be said that Nadi and Sertel fulfill the functions of increasing the sensitivity of the public towards the fifth column, conveying the behavioral patterns they will follow, and providing solidarity through the information they provide, depending on the position they are in, with the column they have. In this respect, these articles can be seen as examples of public relations.

On the other hand, these frameworks that Nadi and Sertel presented to the public on the fifth column also have value in terms of the history of public relations in Turkey. Especially in the literature, while the history of public relations is being explained, Ivy Lee's works are presented as an example while explaining the public information model. In the explana- 
tion of the model, the application examples in Turkey are mostly not encountered. This study has a feature that can be presented as an example for the public information model on Turkey, just after the period when the model was launched. With this characteristic, this study can be seen as valuable in terms of Turkey's public relations history.

\section{Kaynakça / References}

Akbulut, E. (2017). Halkla ilişkilerin tarihsel gelişimi. İçinde F. Geçikli (Ed.), Halkla ilişkiler (s.30-48). Erzurum: Atatürk Üniversitesi Açıöğretim Fakültesi Yayını.

Akdenizli, B. (2012). Gazete haberciliğinde içerik çözümleme yöntem ve tekniği: Sunum ve temsil üzerine bir uygulama. Içinde Ö. Güllüoğlu (Ed.), İletişim bilimlerinde araştırma yöntemleri: Yazılı metin çözümleme (1. Bask1, s.133-162). Ankara: Ütopya.

Atabek, N. (2002). Kamuoyu, medya ve demokrasi. Kurgu, 19(1), 214-229.

Atabek Şendur, G. ve Atabek, Ü. (2007). Medya metinlerini çözümlemek: Içerik, göstergebilim ve söylem çözümleme yöntemleri. Ankara: Siyasal Kitabevi.

Başarir, M. (2020). II. Dünya Savaşı döneminde müttefik devletlere yapılan bir basın gezisinin halkla ilişkiler tarihi, modelleri ve uygulamaları kapsamında analizi. Gümüşhane Üniversitesi İletişim Fakültesi Elektronik Dergisi, 8(2), 961-983. https://doi.org/10.19145/e-gifder.726514.

Berkes, N. (1942). Propaganda nedir?. Ankara: Recep Ulusoğlu Basımevi.

Broom, G. M. and Sha, B. L. (2013). Cutlip and Center's effective public relations (11th ed). Boston: Pearson.

Çetin, B.N. (2016). Propaganda olgusu ve propagandanın amerikanlaşması. Firat Üniversitesi Sosyal Bilimler Dergisi, 24(2), 239-266. https://doi.org/10.18069/fusbed.61313.

Çïfci, M. ve Yildirim, T. (2012). Kâşgarlı Mahmud'un kullandığı temel propaganda teknikleri. Türklük Bilimi Araştırmaları, 32, 33-41.

Çolak, S. ve Aydar, M. (2020). Savaş ve propaganda: 1683 Viyana Kuşatması üzerine bir değerlendirme. Belleten, 84(301), 1045-1096. https://doi.org/10.37879/belleten.2020.1045.

Domenach, J.-M. (1995). Politika ve propaganda (T. Yücel, Çev.). İstanbul: Varlık Yayınları. 
Geçikli, F. (1999). Geçmişten günümüze propaganda kavramı. İstanbul Üniversitesi İletişim Fakültesi Dergisi I Istanbul University Faculty of Communication Journal, 9, 265-276. https://doi.org/10.17064/iüifhd.25289.

Grunig, J. E. (2005). İletişim, halkla ilişkiler ve etkin örgütler: Kitaba genel bir bakış. Içinde J. E. Grunig (Ed.) ve E. Özsayar (Çev.), Halkla ilişkilerde ve iletişim yönetiminde mükemmellik (s.11-42). İstanbul: Rota yayınları.

Güllüoğlu, Ö. (2014). Halkla ilişkiler ve propaganda ilişkisi üzerine kuramsal bir değerlendirme. Selçuk Üniversitesi Sosyal Bilimler Meslek Yüksekokulu Dergisi, 12(1-2), 505-520.

Kapani, M. (1997). Politika bilimine giriş (9. bs). Ankara: Bilgi Yayinevi.

Loeffel, R. (2015). The fifth column in world war II: Suspected subversives in the pacific war and Australia. London: Palgrave Macmillan UK.

MacDonnell, F. (1995). Insidious foes: The Axis Fifth Column and the American home front. UK:Oxford University Press.

Mardin, B. (1988). Halkla ilişkilerin ABD'de gelişimi ve Avrupa'ya girişi. 2126. Halkla İlişkiler Sempozyumu-87, Ankara: Ankara Üniversitesi BasınYayın Yüksekokulu, Türkiye ve Ortadoğu Amme İdaresi Enstitüsü Yayınlart.

Nadi, Y. (1940a, 16 Mayıs). Beşinci kol, hiyanet kolu!... Cumhuriyet, s. 1,6.

Nadi, Y. (1940b, 30 Mayıs). Her memlekette beşinci kol. Cumhuriyet, s. 1,6.

Nadi, Y. (1940c, 5 Haziran). Bütün milletçe tutacağımız tek yol milli birlik yoludur. Cumhuriyet, s.1,6.

Özer, N. P. (2019). Propagandada yöntemler, araçlar ve bir propaganda modeli olarak; Herman ve Chomsky propaganda modeli. Kritik İletişim Çalışmaları Dergisi, 1(1), 15-30.

Özkan, A. (2018). Propaganda çeşitleri. İçinde M. Karaca ve C. Çakı (Ed.), İletişim ve Propaganda (s.75-114). Eğitim yayınevi.

Peltekoğlu, F. (2016). Halkla ilişkiler nedir (9. bs). İstanbul: Beta Yayınları.

Seitel, F. P. (2016). Halkla ilişkiler uygulaması (S. Mengü, Çev.). Ankara:Nobel.

Sertel, M. Z. (1940a, 20 Ağustos). Beşinci kola karşı altıncı kol. Tan, s. 1,2.

Sertel, M. Z. (1940b, 21 Ağustos). Altıncı kolun vazifeleri. Tan, s. 1,2.

Sertel, M. Z. (1940c, 23 Ağustos). Altıncı kol uyanık ve faaliyettedir. Tan, s. 1,2. Sezgin, M. (2007). Meslek yüksekokulları için MEB-YÖK uyumlu halkla ilişkiler (1. bs). Konya: Yücemedya. 
Şehitoğlu, M. ve Doğanay, R. (2019). İran kaynaklarına göre Nazi döneminde almanların iran'daki casusluk ve propaganda faaliyetleri. Firat Üniversitesi Sosyal Bilimler Dergisi, 29(1), 449-465. https://doi.org/10.18069/firatsbed.538773.

Tarhan, A. (2008). Halkla ilişkiler modelleri. İçinde A. Kalender ve M. Fidan (Ed.), Halkla ilişkiler (s.121-144). Konya: Tablet yayınları.

TDK. (2021a). Beşinci kol. https://sozluk.gov.tr/ erişim tarihi: 16.06.2021.

TDK. (2021b). İçinde Şüyuu vukuundan beter. https://sozluk.gov.tr/ erişim tarihi: 28.06.2021.

Terkan, B. (2005). Gündem belirleme: Medya ve siyasal gündem üzerine bir çalışma. Konya: Tablet Kitabevi.

\section{Kaynakça Bilgisi / Citation Information}

Başarır, M. (2021). Beşinci kola karşı halkla ilişkiler: Nadi ve Sertel'in beşinci kola dair kaleme aldıkları köşe yazılarının kamuoyunu bilgilendirme ekseninde analizi. OPUS-Uluslararası Toplum Araştırmalar Dergisi, 18(41), 3654-3678. DOI: 10.26466/opus. 959398. 